\title{
Erratum to: Geological characteristics of the Sizhuang gold deposit in the region of Jiaodong, Shandong Province-A study on tectono- geochemical ore prospecting of ore deposits
}

QIAN Jianping", CHEN Hongyi, and MENG Yong

College of Earth Sciences, Guilin University of Technology, Guangxi, Guilin 541004, China

*Corresponding author,E-mail:jpqian@163.com

Received December 21, 2010; accepted January 10, 2011

(C) Science Press and Institute of Geochemistry, CAS and Springer-Verlag Berlin Heidelberg 2011

Erratum to: Chin.J.Geochem.(2011)30:539-553

DOI: 10.1007/s11631-011-0538-y

In the original article, Fig. 5 is not complete.
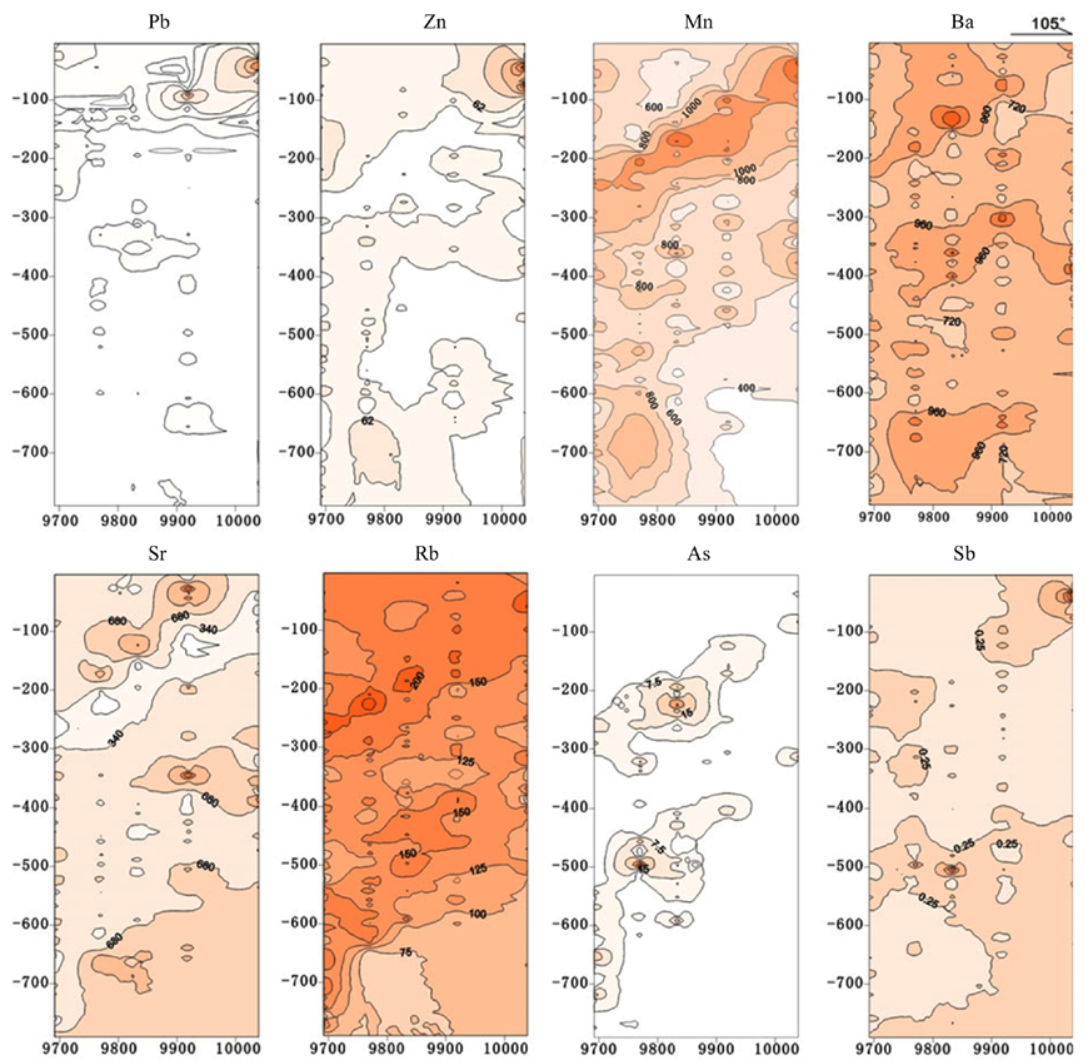

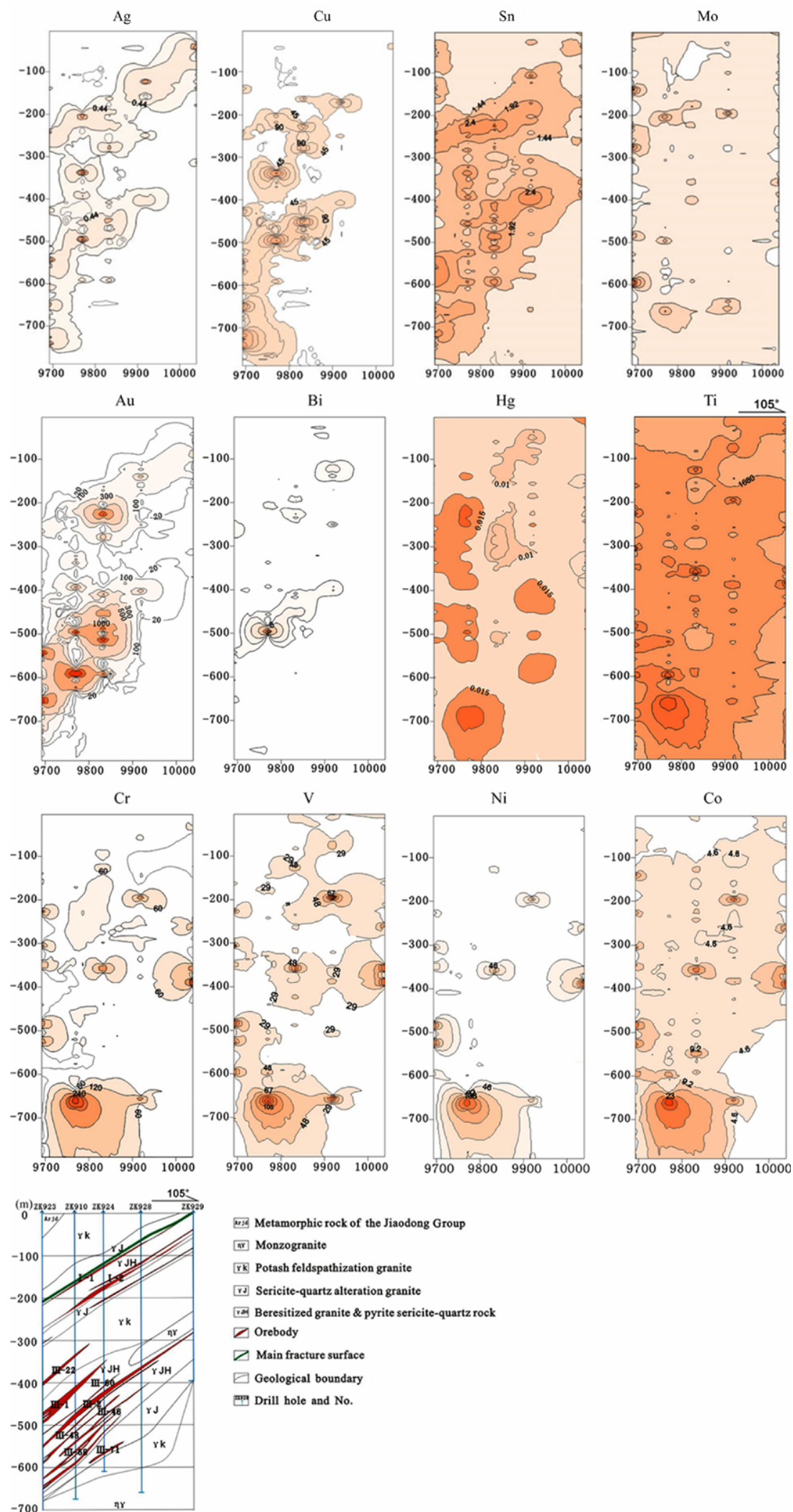

Fig. 5. Transverse section of the orebodies, altered belts and element geochemistry along exploration line No. 304 of the Sizhuang gold mine.

The online version of the original article can be found at http://dx.doi.org/10.1007/s11631-011-0538-y 